\title{
Evaluation of clinical diagnosis of children with acute appendicitis at Rapareen Teaching Hospital
}

\begin{abstract}
Background and objective: Appendicitis is the most common acute surgical emergency of childhood. Decision-making in patients with acute appendicitis poses a diagnostic challenge worldwide. Among the reported diagnostic criteria, modified Alvarado score system and ultrasound findings where used to support diagnosis and even exclude complicated cases. The aim of this study was to detect clinical and sonograghic features that distinguish children visited the emergency department with acute simple appendicitis and idntify factors related to complicated cases.
\end{abstract}

Methods: This cross-sectional study included 76 children with the provisional diagnosis of acute appendicitis according to clinical findings attending the Emergency Departement at Rapareen Teaching Hospital in Erbil between January and December 2012.

Results: Of 76 patients included in this study, 75 patients $(99.7 \%)$ had appendicitis whether inflamed (63 patients, $82.9 \%$ ) or complicated (13 patients, 15.8\%) and only one patient had normal operative (non-inflamed appendix) findings. Delay of admission, high temperature at time of presentation, localized tenderness and MASS of $\geq 7$ increased the risk of complicated appendicitis as do leukocytosis and positive ultrasound findings.

Conclusion: The study shows that use of certain clinical data (like duration of manifestations) with the modified Alvarado score system supported by leukocytosis and positive ultrasound findings in children suspected to have acute appendicitis provides a high degree of diagnostic accuracy of complicated cases rather than simple acute appendicitis.

Keywords: Acute appendicitis; MASS; Children; Ultrasonography.

\section{Introduction}

Acute appendicitis is one of the most common surgical emergencies in both developed and developing countries, with a prevalence of approximately 1 in 7 worldwide. ${ }^{1}$ Its incidence is $1.5-1.9 \backslash 1000$ in male and female population. ${ }^{2}$ Patients with acute appendicitis may present with different symptoms and signs varying from non-specific vague abdominal pain to typical findings of right lower quadrant pain, tenderness and rebound tenderness. ${ }^{3}$ This variability has been attributed to a series of possible causes, including patient's age, inflammation severity and perforation, or a combination of these factors. ${ }^{4}$ The diagnosis of acute appendicitis is purely based on history, clinical examination and some laboratory investigations. Imaging techniques have been shown to add very little. ${ }^{5}$ Surgery for acute appendicitis is the most frequent operation performed $(10 \%)$ of all emergency abdominal operations. ${ }^{6}$ A negative appendectomy rate of $20-40 \%$ has been reported, and many surgeons advocate early surgical intervention for the treatment of acute appendicitis to avoid perforation. ${ }^{7}$ Removing normal appendix is an economic burden on both, patients and health resources. Misdiagnosis and delay in surgery can lead to complications like perforation and finally peritonitis. ${ }^{8}$ Severe periappendiceal inflammation, periappendiceal or abdominopelvic fluid and abscess were significantly associated with perforated appendicitis and with a significant

* Department of surgery, college of medicine, Hawler medical university, Erbil, Iraq.

$* *$ Department of pediatric, college of medicine, Hawler medical university, Erbil, Iraq. 
longer hospital stay. ${ }^{9}$ In order to reduce the negative appendectomy rate, various scoring systems have been developing to support the diagnosis of acute appendicitis. One of the scoring systems is the Alvarado Scoring system that purely based on history, clinical examination and few laboratory tests and is very easy to apply. ${ }^{10}$ The Modified Alvarado Scoring System (MASS) has been reported to be a cheap and quick diagnostic tool in patients with acute appendicitis. ${ }^{11}$ The original Alvarado score describes a possible total of 10 points, but those medical facilities that are unable to perform a differential white blood cell count, are using a Modified Alvarado Score with total score of 9 points, which could be not as accurate as the original score. ${ }^{12}$ The aim of this study was to detect clinical and radiological features that distinguish children visited the emergency department with acute simple appendicitis and identify factors related to complicated cases.

\section{Methods}

A cross-sectional study was performed for all children with the diagnosis of appendicitis proven by operative findings at Rapareen Teaching Hospital in Erbil. Seventy-six children less than 18 years old between January and December 2012 with a provisional diagnosis of acute appendicitis admitted to the emergency department were included in this study. Exclusion criteria included chronic underlying illness and known case of gastrointestinal problem like inflammatory bowel disease. For the purpose of this study, a written official permission has been obtained from Research Ethics Committee of the College of Medicine/Hawler Medical University. Patients with proven appendicitis were divided according to operative findings into two groups: acute simple appendicitis and complicated appendicitis (perforated, gangrenous and with abscess formation). Age, gender, signs and symptoms (pain analysis, tenderness, temperature and associated symptoms), radiologic studies (ultrasound), time of presentation to the emergency department, and operative findings were tabulated and analyzed. Modified Alvarado Scoring System was used (Table 1). ${ }^{13}$ Sonographic findings were classified as:
a. Appendix diameter $\geq 6$
b. Peri-appendicular fat tissue inflammation
c. Peri-cecal fluid or abscess formation
d. Both a. and c.
e. Others (Blind-ended tubular structure, Non compressible , Appendicolith ,....... $)^{14}$ ' Statistical package for the social sciences (version 21.0) was used for analysis with t-test to compare means and chi-squared test for categorical variables to check the relationship between clinical features, radiological findings and operative findings.

A $P$ value of $\leq 0.05$ was considered statistically significant. OR (odds ratio) with $\mathrm{Cl}$ (confidence intervals) were computed for a $2 \times 2$ table to estimate risk. Medcalc Version 12.7.7 software for windows used for claculating sensitivity and specificty.

Table 1: the Alvarado and Modified Alvarado Score

\begin{tabular}{|c|c|c|c|}
\hline & & Alvarado & $\begin{array}{l}\text { Modified } \\
\text { Alvarado }\end{array}$ \\
\hline \multirow[t]{3}{*}{ Symptoms } & $\begin{array}{l}\text { Migratory RIF } \\
\text { pain }\end{array}$ & 1 & 1 \\
\hline & Anorexia & 1 & 1 \\
\hline & $\begin{array}{l}\text { Nausea / } \\
\text { vomiting }\end{array}$ & 1 & 1 \\
\hline \multirow[t]{3}{*}{ Signs } & Tender RIF & 2 & 2 \\
\hline & $\begin{array}{l}\text { Rebound } \\
\text { tenderness } \\
\text { RIF }\end{array}$ & 1 & 1 \\
\hline & $\begin{array}{l}\text { Elevated } \\
\text { temperature } \\
>37.5\end{array}$ & 1 & 1 \\
\hline \multirow{2}{*}{$\begin{array}{l}\text { Laboratory } \\
\text { investigations }\end{array}$} & Leucocytosis & 2 & 2 \\
\hline & $\begin{array}{l}\text { Shift to left } \\
\text { neutrofils }\end{array}$ & 1 & - \\
\hline Total score & & 10 & 9 \\
\hline
\end{tabular}




\section{Results}

Among 76 patients included in this study, 75 patients $(98.7 \%)$ had appendicitis whether inflamed (63 patients, $82.9 \%$ ) or complicated (12 patients, 15.8\%) and only one patient had normal operative (non-inflamed appendix) as shown in Table 2.

Table 2: Clinical manifestations and laboratory findings of suspected patients.

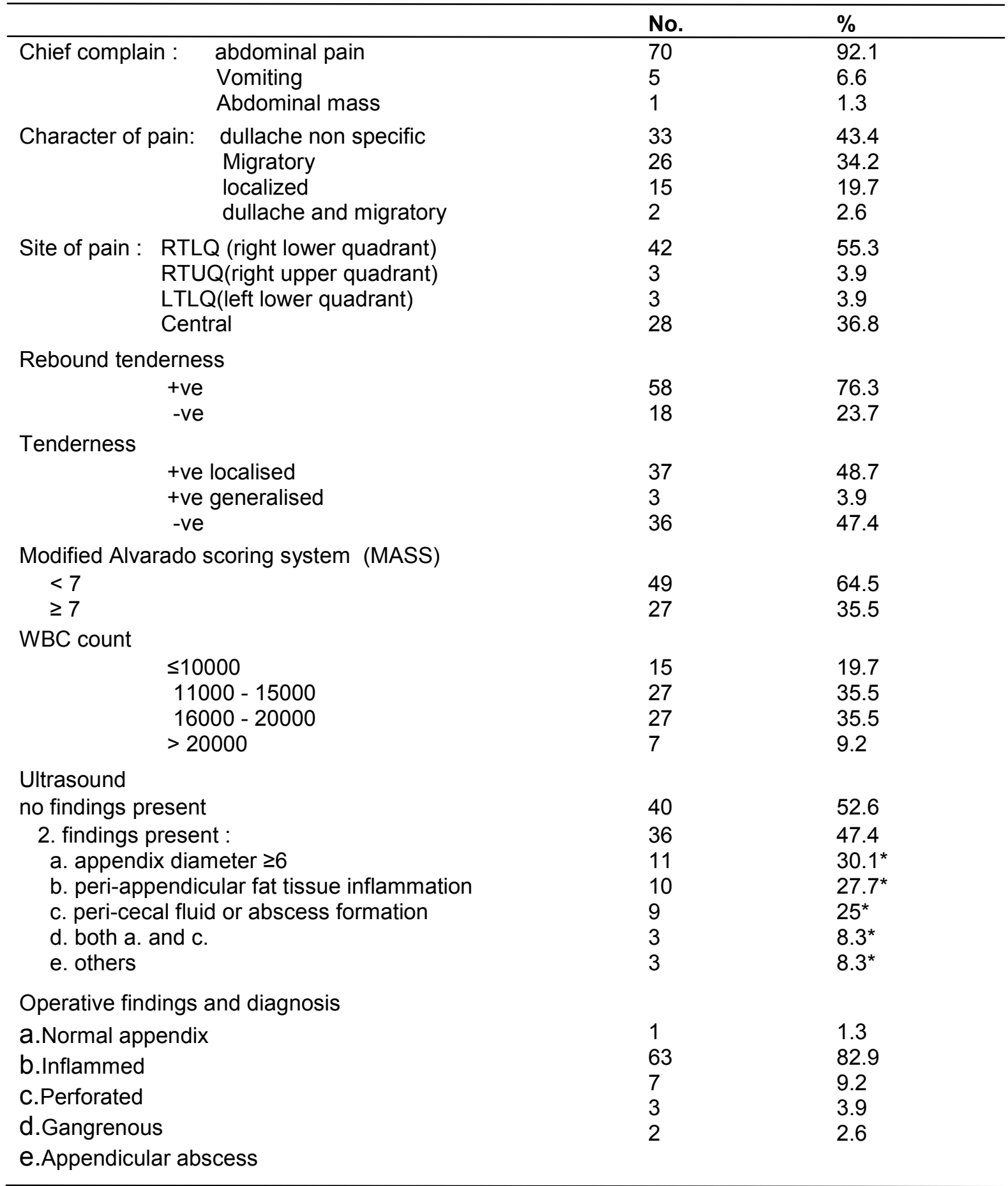

* Percentage among positive ultrasound findings 
This only patient was a male 11 years old complaining of localized right quadrant pain of 3 days duration with localized tenderness but no rebound tenderness with temperature of $36.6 \mathrm{C} \circ$, alvarado score of 3 and no leukocytosis or sonographic findings of appendicitis. Fifty seven out of 76 suspected appendicitis $(75 \%)$ were of age group (5-10 years) while only 7 were below 5 year of age $(9.2 \%)$. Most of patients had abdominal pain $(92.1 \%)$ as chief complain which was mainly dull ache non specific (43.4\%), at lower right quadrant of abdomen (55.3\%) with positive rebound tenderness (76.3\%) and MASS of $<7$ in $64.5 \%$, while 36
$(47.4 \%)$ patients had ultrasound findings supportive of appendicitis diagnosis and $19.7 \%$ had low white blood cells count of less than or equal to 10000 (Table 2). In Table 3 and 4 , after excluding the only patient with normal operative finding; cases of inflamed versus complicated appendicitis were compared by certain variables. Larger duration before time of admission, high temperature at time of admission, localized tenderness and MASS $\geq 7$ (OR 14.68, Cl: 2.91-74.27) increased the risk of complicated appendicitis as do leukocytosis (OR and $\mathrm{Cl}$ not applicable) and positive ultrasound findings (OR 16.7, Cl: 2.03-137.7).

Table 3: Association of certain demographic, clinical and laboratory variables with underlying operative findings.

\begin{tabular}{lllll}
\hline Variables & & Inflamed & Complicated & $\mathbf{p}$ \\
\hline Gender & Male & $39(79.6 \%)$ & $10(20.4 \%)$ & 0.15 \\
& Female & $24(92.3 \%)$ & $2(7.7 \%)$ & \\
Age in years & $\leq 10$ years & $54(84.4 \%)$ & $10(15.6 \%)$ & 0.83 \\
& $>10$ years & $9(81.8 \%)$ & $2(18.2 \%)$ & \\
Tenderness & localised & $28(77.8 \%)$ & $8(22.2 \%)$ & 0.008 \\
& generalised & $1(33.3 \%)$ & $2(66.7 \%)$ & \\
MASS & Absent & $34(94.4 \%)$ & $2(5.6 \%)$ & \\
& $<7$ & $47(95.9 \%)$ & $2(4.1 \%)$ & $<0.001$ \\
WBC & $\geq 7$ & $16(61.5 \%)$ & $10(38.5 \%)$ & \\
& $\leq 10000$ & $14(93.3 \%)$ & $1(6.7 \%)$ & 0.016 \\
& $11000-15000$ & $22(84.6 \%)$ & $4(15.4 \%)$ & \\
& $16000-20000$ & $24(88.9 \%)$ & $3(11.1 \%)$ & \\
Ultrsound findings & $>20000$ & $3(42.9 \%)$ & $4(57.1 \%)$ & \\
& $-v e$ & $38(97.4 \%)$ & $1(2.6 \%)$ & 0.001 \\
& $+v e$ & $25(69.4 \%)$ & $11(30.6 \%)$ & \\
\hline
\end{tabular}

Table 4: T Test for comparing between means of inflammed compared to complicated cases

\begin{tabular}{llll}
\hline & Inflamed & Complicated & p \\
\hline $\begin{array}{l}\text { Duration before addmission in hours } \\
\text { (mean } \pm \text { SD) }\end{array}$ & $24.20( \pm 15.74)$ & $53.66( \pm 28.19)$ & $<0.001$ \\
$\begin{array}{l}\text { Temperature at time of admission in Celsius } \\
(\text { mean } \pm \text { SD) }\end{array}$ & $37.95( \pm 0.68)$ & $38.46( \pm 0.74)$ & 0.02 \\
\hline \hline
\end{tabular}


Both sensitivity and specificity of MASS and ultrasound were $(83.3 \%, 74.6 \%)$ and $(91.67 \%, 60.32 \%)$ respectively. Agreement was $76 \%$ for MASS and $65 \%$ for ultrasound (Tables 5 and 6).

Table 5: MASS versus operative findings.

\begin{tabular}{cccc}
\hline MASS & $\begin{array}{c}\text { Complicated } \\
\text { appendicitis }\end{array}$ & $\begin{array}{c}\text { Inflamed } \\
\text { appendix }\end{array}$ & Total \\
\hline$\geq 7$ & 10 & 16 & 26 \\
$<7$ & 2 & 47 & 49 \\
Total & 12 & 63 & 75 \\
\hline
\end{tabular}

Sensitivity: $83.33 \%(95 \% \mathrm{Cl}: 51.58 \%$ to $97.42 \%)$ Specificty: $74.60 \%$ (95\% Cl: $62.06 \%$ to $84.73 \%$ ) Positive predictive value: $38.46 \%(95 \% \mathrm{Cl}: 20.25$ $\%$ to $59.42 \%$ )

Negative predictive value: $95.92 \%(95 \% \mathrm{Cl}: 85.99$ $\%$ to $99.38 \%$ )

Table 6: Ultrasound findings versu operative findings.

\begin{tabular}{llll}
\hline U/S & $\begin{array}{l}\text { Complicated } \\
\text { appendicitis }\end{array}$ & $\begin{array}{l}\text { Inflamed } \\
\text { appendix }\end{array}$ & Total \\
\hline +ve findings & 11 & 25 & 36 \\
-ve findings & 1 & 38 & 39 \\
Total & 12 & 63 & 75 \\
\hline
\end{tabular}

Sensitivity: $91.67 \%$ (95\% Cl: $61.46 \%$ to $98.61 \%)$ Specificty: $60.32 \%$ (95\% Cl: $47.20 \%$ to $72.43 \%$ ) Positive predictive value: $30.56 \%(95 \% \mathrm{Cl}: 16.37$ $\%$ to $48.11 \%$ )

Negative predictive value: $97.44 \%(95 \% \mathrm{Cl}: 86.47$ $\%$ to $99.57 \%$ )

\section{Discussion}

This study was conducted to evaluate the diagnostic value of MASS and other laboratory findings in patients with acute simple and complicated appendicitis. The goal of the clinical decision process in patients with acute abdominal pain is to make a correct diagnosis in the fastest and cheapest way. ${ }^{15}$ The male predominance in this study is in agreement with the finding of other studies conducted previously. ${ }^{8,16,17}$ This may be attributed to the fact that female patients with right iliac fossa pain have a wide range of differential diagnosis as a result acute appendicitis may be overdiagnosed. The results of Khawaja et al, ${ }^{18}$ who conducted a study at Muhammed Medical College in Pakistan, and found that out of 100 patients, 62 patients $(62 \%)$ had a MASS score of $>7$, among them 15 patients $(24 \%)$ were females and 47 patients $(76 \%)$ were males. Kanumaba et $\mathrm{al}^{19}$ conducted a study including adults and children and found that simple appendicitis was equally in all age groups, whereas children aged $0-15$ years had significant higher perforation rate compared to other age groups whereas our study showed no significant relation with equal incidence of complicated and simple appendicitis at different age groups. This may be attributed to having our study being restricted to children only, while another study of 204 children $^{20}$ support our findings. The commonest symptom was abdominal pain $(92.1 \%)$ followed by vomiting. This is comparable with other studies in which children presented with abdominal pain (89-100\%), fever (80-87\%) and vomiting (66-100\%), though our results showed that localized abdominal pain was less common compared to migratory pain. ${ }^{21}$ This may be explained by difficulty in description of pain by younger children like those below 5 years of age who were included in our study. Again migratory abdominal pain mainly in right lower quadrant or tenderness was the commonest presentation in other studies ${ }^{22}$ as expected. Several authors stress that the presence of right lower quadrant tenderness is probably the most sensitive physical finding in early appendicitis. ${ }^{23}$ Localized tenderness $(48.7 \%)$ with rebound tenderness (76.3\%) showed in this study is nearly equal to findings of a study in which $43 \%$ of patients had lower quadrant localized tenderness, with rebound tenderness in $75 \% .{ }^{24}$ Our operative findings were nearly similar to a study by Hameed and Merdan ${ }^{25}$ as inflamed appendix and complicated were $79 \%$ and $27.3 \%$ respectively while normal 
appendix was $2.4 \%$. Inflamed appendix was the most common operative findings $(62.9 \%, 51.2 \%)^{19,23}$ followed by perforated appendices, gangrenous appendices and lastly abscess as shown in previous studies, ${ }^{19,23}$, which supports our operative findings. The diagnostic accuracy for pediatric appendicitis was high (up to $80 \%$ ) with mean WBC count was > $14.8 \times 104 /$ L. $^{16}$ Physicians should not discount appendicitis in children with vomiting and laboratory evidence of leucocytosis, especially in those over five years of age. In our study WBC count (80.2\%) where above 10000/L which nearly equal to findings of study of Sadidique et al where Leukocytes count was $\geq 10 x 109 / \mathrm{L}$ in $75.43 \%$ of cases and even higher WBC may be helpful in predicting complicated cases (mean of 13800 versus 15000/L) compairing acute simple appendicitis and perforated appendix respectively. ${ }^{20}$ Perforation correlates strongly with delayed diagnosis. ${ }^{26}$ The risk of perforation is highest in the first four years of life and has been reported in more than 70 percent of children in this age group $^{27}$ while most of patients in this study were below 10 years with perforated appendix constitute 2 among 7 patients below 5 years of age; this finding was consistent with many studies e.g. Chung et $\mathrm{al}^{28}$ and Bickell et $\mathrm{al}^{29}$ that had reported perforation rate were more in children $\leq 4$ years. Longer duration of manifestations is assoicated with increased risk of complications, especially rate of appendiceal perforation in the misdiagnosed cases in this study, a similar findings were seen by Chung et $\mathrm{al}^{28}$ and Bickell et al. ${ }^{29}$ In latter study, the duration of illness in majority of patients was four days and seen by the admitting doctor in more than 24 hours after the onset of illness. This observation concurs with other reports. ${ }^{8,12}$ The reasons for delay in seeking medical consultation in this study may be attributed to delay in referral from primary or secondary health centres, misdiagnosis or fear of surgery as a result they are treated conservatively with analgesics and antibiotics to mask the symptoms. Delayed presentation is associated with increased morbidity and mortality due to appendiceal perforations and peritonitis. A high temperature ( $\geq 38 \mathrm{C}^{\circ}$ ) and a long duration of symptoms were associated with complicated appendicitis like perforation which is compatible with our study. ${ }^{20,21}$ The rate of perforation in our study was $7.9 \%$, which is comparable to other reported rates $9.4 \%{ }^{26,27}$ However, much higher perforation rates have been reported from other centres in Nigeria. ${ }^{16}$ Several studies validated the Modified Alvarado Score System using different cut-off points as by Bukhari and Rana ${ }^{30}$ where the cut-off points was 7 and (83\%) of the patients had MASS of $\geq 7$; in this study, $35.5 \%$ had MASS of $\geq 7$ and this may be explained that most of patients were treated initially with symptomatic treatment and even with antibitotics as they were considered as URTI. Around $80 \%$ of perforation of appendices occurred mostly in patients with MASS $\geq 7$ and this may determine role of MASS in early detection of perforated or complicated appendicitis. Despite limited studies support this findings as most articles focus on role of MASS in differentiating nromal from inflammed appendix regardless if complicated or not, but Dey etal found That there were 6 patients with gangrenous appendicitis, 4 had perforated appendicitis in a retrospective study conducted in the Department of Surgery of a Medical College Hospital in Gangtokand and they all were within the score range (MASS) of $\geq 7 .{ }^{31}$ Ultrasound features of appendicitis were positive in $39.7 \%$ of cases and negative in $60.3 \%$, while in another study ${ }^{32}$ it was positive in $54.2 \%$ and negative in $45.8 \%$, such difference may be related to variation in sample size, age groups and time of doing ultrasound after had clinical features as we lack emergency ultrasound in most of night shift. Of the 55 patients with visualized appendix in the group with a final diagnosis of appendicitis, ${ }^{33}$ most patients had an appendiceal diameter 
of $\geq 6 \mathrm{~mm}$ and this support our finding of a diameter of $\geq 6 \mathrm{~mm}$ as the commonest sonographic finding (11 out of 36 ). To determine the effectiveness of ultrasound at differentiating perforated from nonperforated appendicitis in children, Levin and colleagues $^{34}$ conducted a retrospective study of 161 consecutively registered children (mean age of 11 years) who had acute appendicitis and had undergone ultrasound and appendectomy. An abscess on ultrasound was associated with perforation, featuring a sensitivity of $36.2 \%$ and a specificity of $99 \%$ and ultrasound considered effective for differentiation of perforated from nonperforated appendicitis in children as in our study. Limitations of this study must be considered. The study design was based on a cross sectional evaluation of several ultrasound and clinical criteria, but lack histopathoological findings which recommended in future studies.

\section{Conclusion}

This study shows certain clinical data like duration of manifestations with high MASS supported by leukocytosis and positive ultrasound findings in children suspected to have acute appendicitis can help to identify those with complicated appendicitis from simple inflamed appendix.

\section{Conflicts of interest}

The authors report no conflicts of interest.

\section{References}

1. Mohammed AA, Daghan NA, Abouds M. The diagnosis value of C-reactive protein, white blood cell count and neutrophils percentage in childhood appendicitis . Saudi Med J 2004 ;25:1212-5.

2. Cuschieri A.The small intestine and vermiform appendix .In: Giles GR, Mossa AR Essential surgical practice $3^{\text {rd }}$ ed. London: Butter worth Heinemann; 1995:1325 -8.

3. Schwartz SI. Appendix. In: Schwartz SI, Shires GT, Spencer FC. Principles of surgery, $5^{\text {th }}$ ed. New York: Mc Graw - Hill; 1989: P.1315.

4. Prukprasert $P$, Maipang T, Greater A, Apakupakul $\mathrm{N}$, Ksantigi JP. Accuracy in diagnosis of appendicitis by Comparing $\mathrm{C}$ - reactive protein measurement, Alvarado score and clinical impression of surgeons. J Med Assoc Thail $2004 ; 25: 296-303$.
5. Dado G, Anania G, Baccarani U, Macrotti E, Donini A , Risaliti A. Application of a clinical score for the diagnosis of acute appendicitis in childhood. J Pediatr Surg 2000; 35:1320-2.

6. Matthyssens LE, Ziol M, Barrat C, Champault G.Routine Surgical Pathology in General. $\mathrm{Br} \mathrm{J}$ Surj 2006 ; 93:362-8 .

7. Kalan M, Talbot D, Cunliffe WJ, Rich AJ. Evaluation of the MASS in the diagnosis of acute appendicitis : a prospective study . Ann R Coll Surg 1994; 76: $418-9$.

8. Ohmann C, Yang Q, Franke C. Diagnostic scores for acute appendicitis. Eur J Surg 1995;161:273-81.

9. Siddiqui $A H$, Afzal $S$.Perforated appendicitis: accuracy of ct diagnosis and correlation CT findings with the length of hospital stay. J Coll Physicians Surg Pak. 2007; 17(12):721-5.

10. Alvarado A. A practical score for the early diagnosis of acute appendicitis. Ann Emerg $1986 ; 15: 557-65$.

11. Fenyo $G$, Lindberg $G$, Blind $P$, Enochsson $L$, Oberg A: Diagnostic decision support in suspected acute appendicitis : Validation of a simplified scoring system . Eur J Surg Med 1997; 163:831-8 .

12. Khan I, Rehman A. Application of Alvarado scoring system in diagnosis of acute appendicitis. J Ayub Med Coll Abottabad 2005;17: 41-4.

13. Almujamaee B. the assesment of modified Alvarado Score in the diagnosis of acute appendicitis. Diyala J Med 2011; 1(1): 1-5.

14. Hassan M, Tawfiq S, Brayyich A, Aljabbar L. The sensitivity and specificity of ultrasound in diagnosis of acute appendicitis. Tikrit Med J 2009; 15(2):132-40

15. Hoffmann J, Rasmussen 00 . Aids in the diagnosis of acute appendicitis. Br J Surg 1989; 76: 774-9.

16. Edino ST, Mohammed AZ, Ochicha O, Anumah M. Appendicitis in Kano, Nigeria: A 5 yr. review of pattern, morbidity and mortality. Ann Afr Med 2004, 3:38-41.

17. Beltra'n MA, Almonacid J, Vicencio A, Gutie'rrez $\mathrm{J}$, Cruces KS, Cumsille MA. Predictive value of white blood cellcount and C-reactive protein in children with appendicitis. J Paediatr Surg 2007; 42:1208-14.

18.Khawaja AM, Khoohoro $\mathrm{Y}$, Majeed N. The Alvarado Score for the diagnosis of acute appendicitis at Muhammed Medical College Hospital Mirpurkhas. Evaluation of validity of Alvarado Scoring System for diagnosis of acute appendicitis. Pak J Med Sci 2009;25.

19. Kanumba E, Mabula1J, Rambau P,Chalya P. Modified Alvarado Scoring System as a diagnostic tool for Acute Appendicitis at Bugando Medical Centre, Mwanza, Tanzania. BMC Surgery 2011, 11(4):1-5.

20.Siddique K, Baruah P,Bhandari S, Mirza S, Harinath G. Diagnostic accuracy of white cell 
count and C-reactive protein for assessing the severity of paediatric appendicitis.J R Soc Med Sh Rep 2011; 2:59.

21.Rothrock SG, Pagane J. Acute appendicitis in children:emergency department diagnosis and management. AnnEmerg Med 2000; 36:39-51

22. Williams N, Kapila L. Acute appendicitis in the preschool child. BMJ 1991;66:1270.

23. Velanovich $V$, Savata $R$. Balancing the normal appendectomy rate with the perforated appendicitis rate: implications for quality assurance. Am Surg 1992; 58:264-9.

24. Colvin JM, Bachur R, Kharbanda $A$. The presentation of appendicitis in preadolescent children. Pediatr Emerg Care 2007; 23:849-55.

25. Hameed $\mathrm{H} \&$ Merdan $\mathrm{I}$.the effectiveness of ultrasound imaging in the diagnosis of acute appendicitis. Bas J Surg. 2012;18: 89-96.

26. Blisard D: Istitutioning a clinical guideline to decrease the rate of negative appendicectomy. American Surgeon 2003, 69:796-8.

27.Larsson PG, Tronstard SE: Laparoscopy reduces unnecessary appendicectomy and improves diagnosis in fertile woman. ARandomized study. Surgical endoscopy 2001, 15:200-2.

28. Chung $\mathrm{CH}, \mathrm{CP} \mathrm{Ng}$, Lai $\mathrm{K}$. Delay by patient ,emergency physician ,and surgeon in management of acute appendicitis. HK MJ September $2000 ; 6$ (3).

29. Bickell NA et al .How time affects the risk of rupture in appendicitis. J Am Coll Surg 2006; 202 (3); 401-6.

30. Bukhari SAH, Rana SH. Alvarado Score. A new approach to acute appendicitis. Pak Armed Forces Med J $2002 ;$ 52:47-50.

31. Dey S, Mohanta P, Singh V.Alvarado Scoring in Acute Appendicitis :Clinicopathological Correlation. Indian J Surg 2010 August; 72(4): 290-3.

32. Sivit C. Imaging children with acute right lower quadrant pain. Pediatr Clin North Am 1997; 44: 575-89.

33. Ameen MK. Ultrasound Evaluation of Suspected Appendicitis. J Fac Med Baghdad 2007; 49(1): 95-100

34. Blumfield E, Nayak G, Sirinivasan R, Muranaka MT, Blitman NM, Blumfield A etal. Ultrasound for differentiation between perforated and nonperforated appendicitis in pediatric patients. AJR 2013; 200(5):957-60. 